THE INTERNATIONAL

REVIEW OF RESEARCH IN

OPEN AND DISTANCE LEARNING

\title{
Liminality and Disinhibition in Online Language Learning
}

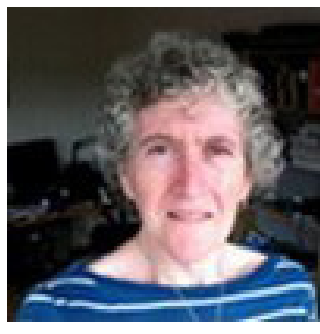

Una Cunningham

Stockholm University, Sweden

\section{Abstract}

The aim of this paper is to bring theoretical concepts from other areas of scholarly research to bear on synchronous online education in a cross-disciplinary effort to shed light on what is going on by introducing systems of thought from other areas. The liminality and associated communitas which are found in synchronous online learning environments are examined for their possible consequences for learning in general and language learning in particular. Like computer-mediated communication, liminality has been associated with disinhibitory effects. Lack of excessive inhibition has been shown to have positive effects on second language production. The position of the online learner as "neither here nor there" or perhaps simultaneously both here and there is investigated and discussed.

Keywords: Distance universities; higher education; e-learning; CMC; liminality; disinhibition; language learning; online learning; computer-mediated communication

Imagine an octagonal room with a door in each of its eight walls. The room contains a round table with eight chairs at it. All eight doors are open, and you can see where they lead. Through the first door you see a Swedish pine forest, covered in a deep blanket of snow; the next door leads to a bustling, noisy market scene in a village in the foothills of the Hindu Kush; the third door opens onto a very hot Internet café at the edge of a windswept desert with pyramids on the horizon; the fourth door opens onto the hooting, seething traffic of central Hanoi; the fifth to a bedroom bathed in the morning sun, high up in a skyscraper in Buenos Aires; the sixth to a mountain monastery in Catalonia; the seventh to an apartment in Hong Kong; and the eighth leads onto a beautiful beach on Australia's west coast with the surf rolling in under the moonlight. A few minutes before the appointed hour, people start coming into the room and sitting down. In Buenos Aires it is 9 a.m. and Ana has just 
had breakfast. It is 1 p.m. at the monastery in Catalonia, but it will not be lunchtime for a couple of hours for Brother Xavier. In Egypt it is 2 p.m. and Hoda is looking a little warm; in northern Pakistan it is 5 p.m.-Hussain has just finished work for the day and steps in from the market square where everything has been packed up for the night. In Hanoi it is 7 p.m. and dark as Thu slips into her seat; in Hong Kong it is 8 p.m. and Christine has just settled her son in front of the TV so she can join the group; and in Australia it is 10 p.m. and the beach is dark and deserted, though Ben is still wearing his shorts and flip-flops. The seven students know each other already and start chitchatting about the weather (always an interesting topic, as they live in such different conditions) and about the reading they had to do to prepare for the class. Since the last time they met (a week ago), they have posted their reading reflections on the forum discussion page on Fronter, their university's learning platform, and they have been busy commenting on each other's writing. When Una, the teacher, steps into the room, it is 1 p.m. in Sweden and she has just come back to her office after lunch. The students are already deep in discussion about a point raised by Thu with which Ben is quite unable to agree. The seven students are eager to ask questions that have arisen in their discussions since the last class and to have the teacher give her thoughts on the dispute.

This description is neither from a computer-based role-playing game nor from the Arabian Nights or any other tale of fantasy. The learning situation described here is not unusual if we consider that the seminar room does not have a physical reality. Students anywhere can use desktop technology such as Adobe Connect to come together in real time for synchronous seminars, without needing to make a physical journey to the university and its classrooms. The interface between their own physical space and the virtual space of the seminar room is the networked computer rather than a door, but the feeling is very much the same. The students are able to hear a certain amount of background noise from each location when that participant activates his or her microphone. The sound of waves on the Australian beach will compete with the traffic noise in Hanoi for students' attention.

The advantages of this virtual communication are legion-economy, safety, comfort, convenience, and, not least, minimal use of resources. There are disadvantages, of course, many of which have been described at length in this journal, but for many students this kind of online learning is possible in situations where university study would not otherwise be feasible. The globalization of education has led to the existence of the kind of classroom demography described here. Particularly at the postgraduate level, students trawl the Net in search of courses that meet their needs and that they can credit to the degree program they are taking at their home university, which may or may not be closer to home. Swedish universities have been particularly attractive in this global market as they are only now (autumn, 2011) introducing application and tuition fees, and then only for students from outside the EU.

The meeting of students from many different locations at a single point in absolute time is fairly new. Until recently, the technology involved in this kind of meeting was cumbersome and prohibitively expensive. There are a number of qualitative differences between synchronous and asynchronous meetings and also between text-based and multimodal meet- 
ing environments. This kind of meeting does bring with it some consequences, however, which may-and probably do-have an effect on learning in general and on language learning in particular. The aim of this paper is to bring theoretical concepts from other areas of scholarly research to bear on synchronous online education in a cross-disciplinary effort to shed light on what is happening. In turn, I will consider liminality, disinhibition, social presence, and another effect I call quantum education.

\section{Liminality}

The concept of liminality, from the Latin limens (threshold), was first introduced in anthropology by van Gennep (1960) and was later refined by Turner $(1967,1969)$. Turner referred to liminality in the specific context of rites of passage in the literal sense. In a much quoted and misquoted sentence, Turner (1969) writes, "Liminal entities are neither here nor there; they are betwixt and between the positions assigned and arrayed by law, custom, convention and ceremonial" (p. 95). Turner further describes the "communitas" experienced in the liminal period as "a community or even communion of equal individuals who submit together to the general authority of the ritual elders" (p.96).

The applicability of this conceptual framework to our octagonal room with its round, nonhierarchical table is striking, and the "ritual elder" here is of course the seminar leader, or perhaps the university itself. The participants in the seminar are removed from their normal positions in their physical reality but they will return there-perhaps changed in some way-after the seminar. The communitas of the seminar room is fundamental to modern sociocommunicative theories of learning, and the non-hierarchical meeting of equals is integral to the kind of supportive and permissive learning environment to which modern university seminars aspire.

Since Turner's work, the concept of liminality has been extended and stretched almost out of recognition to cover anything from a process from one state to another to the feeling of being in some sense marginal, as in the homeless, who are referred to as "separated from one social category and...suspended in an intermediate status before crossing over into another category" (Wingate-Lewinson, Hopps, \& Reeves, 2010), or the mobility experienced by Brazilian truck drivers (Lippman et al., 2007).

The octagonal seminar room is a liminal space by all these definitions. Participants are in a sense removed from their mundane day-to-day lives with their associated packages of rights, duties, and norms, yet at the same time they remain in the physical space of their day-to-day lives. The norms that apply here in the virtual seminar room are new-set by the environment and by the requirements of the Swedish university-yet, at the same time, the participants are subject to the norms imposed by their physical environment and their day-to-day lives that may in fact be continuing around them. The participants are detached and thus free in the sense that their minds and senses are occupied by the seminar. They are set up for the transitional experience of learning and will return from the experience changed. Each of them is part of the communal seminar experience. The actions of each affect the whole. 


\section{Liminal Disinhibition}

The anthropologist, Turner (1969, p. 104), describes a liminal space characterized by sexual continence that was created in the Ndembu installation rites. Unlike in this space, other kinds of liminal contexts can have different effects. The matter of reduced responsibility may account to some extent for the feeling of not having to conform to the constraints of everyday life. Lippman et al. (2007) associate the liminal environment of truck drivers who regularly cross borders with reduced sexual responsibility "through (the) perception of greater autonomy and distance from traditional norms" (p. 2465). They measured the extent to which truck drivers in this particular context agreed with statements such as, "I feel like I am a different person when I am on the road," "When I am on the road I can do things that I don't do at home," and "When I am on the road I don't have anyone telling me what to do." They relate this change in attitude to similar documented effects found in the behaviour of young tourists, who are temporarily removed from their day-to-day lives (Apostolopoulos, Sonmez, \& Yu, 2002; Eiser \& Ford, 1995; Ford \& Eiser, 1996). While they were backpacking, the young tourists studied by these scholars also felt freed from the norms by which they usually abide. The idea of a holiday romance or casual sex while away from home can thus be explained by the removal from the familiar environment and by the assurance that this is a temporary state from which the travellers will eventually return, back to norms and normality. Applied to the non-physical experience of the online seminar, we might expect the feeling of reduced responsibility to be reflected in a reduced wariness and perhaps a greater willingness to take risks as a student. Risk-taking is a necessary part of successful language learning where student activity is required for learning to take place (Swain, 1985; Naiman, Frölich, Stern, \& Todesco, 1995).

\section{Net-Based Communication and Disinhibition}

Disinhibitory effects have previously been noted in computer-mediated communication (CMC) (e.g., Suler, 2004; Joinson, 2003). Joinson (1998) defined disinhibition on the Internet as "any behaviour that is characterized by an apparent reduction in concerns for selfpresentation and judgement of others" (p. 44). This disinhibition has in some contexts led to aggressive behaviour, such as verbal aggression (Dyer, Green, Pitts, \& Milward, 1995). Angeli and Brahnam (2008) found that people interacting with computers emulating conversational partners (chatterbots) were in fact often very rude to them.

Thurlow, Lengel, and Tomic (2004) reject the notion that the fact that CMC is less information-rich than face-to-face communication is enough to evoke "an endless stream of rude, insulting, aggressive and inflammatory remarks," (p. 70) since other limited forms of communication, such as letter-writing, do not. This has been associated with the perceived anonymity of computer-mediated communication at a time when such communication was primarily text-based (Joinson, 1998). Thurlow et al. (2004) point out that participants report a perception of freedom from constraints and responsibility in CMC, such that people can feel less self-conscious about their appearance and more inclined to disclose things about themselves. The freedom from responsibility has been seen in connection with a response to reduced social cues. The reduced social cues (RSC) model was proposed by Sproull and Keisler (1986) and by Keisler and Sproull (1992) to explain the negative impact of computer 
mediation on group processes. The RSC model referred specifically to text-based interaction, and the main idea was that the reduction in social cues leads to more effortful conversation, which is also more task-focussed. This then leads to more self-absorption and a lack of inhibition, which makes CMC "undermine social norms and influences" (Thurlow et al., 2004, p. 61). Thurlow et al. (2004) relate this to the social psychological concept of de-individuation, where the group activity "becomes more important and the individual's self- awareness diminishes" and the group "takes on a mind of its own" (p. 63). This might in turn tie back into what Turner (1969) called communitas.

Joinson (1998) points out that disinhibition cannot be assumed to occur in all online contexts. In a study of community in (text-based asynchronous) online learning, Conrad (2002a) claims "there is no anonymity in online learning" (p. 8). She writes that the online learners' commitment to their program "created in them an increased sense of inhibition" (p. 9). It is unclear whether she is comparing the online classroom to the face-to-face classroom or to other anonymous and casual online activities. In the former case, I would argue that the reduced self-revelation afforded by the virtual environment, along with the possibility of physically remaining in a familiar and secure environment, are anyhow less inhibiting than the physical classroom environment. Multimodality of the environment allows participation through text and no need to participate in stressful, face-threatening competition for the floor (Cunningham, Beers Fägersten, \& Holmsten, 2010).

There are also studies that reflect on the positive effects of disinhibition. A study by Roberts, Smith, and Pollock (2000) found that shy people found it easier to open up online and even offline after the online experience. Rice and Markey (2009) and High and Caplan (2009) found that anonymous text-chat conversations with strangers were perceived as less stressful than similar face-to-face conversations. Shepherd and Edelmann (2005) found that the Internet was a useful channel for social engagement for students who experience social anxiety. For some students, technology itself is stressful, though this is likely to become less of a problem as the number of students who are unfamiliar with computers and the Internet decreases. Conrad (2002b) tells of students who experience anxiety and a great need for information before embarking on a text-based Net-based course without synchronous meetings.

My own experience of multimodal synchronous seminar tools such as Adobe Connect is that students who are not obliged to use a webcam will generally prefer not to. Students have expressed appreciation of the option to be present in voice but not video. As one student put it, "I can take part in my pyjamas and no one is any the wiser." I have enabled a student with Asperger's syndrome to take part in my course by assuring him that he would not have to use a webcam. He felt that as long as he could not be seen, he was not as exposed to his classmates. He would not have been able to attend a campus course. Even if the Net-based students are not anonymous in the sense that they appear in the virtual seminar room using their own names, they do not know each other, and while many students do get to know their online classmates and meet up online or in real life outside class, most do not. Conrad (2002a) reports findings indicating that learners who have been part of a text-based online learning community for a long time (as might be the case with degree programs that con- 
tinue for several years) may feel "a sense of wariness about what they committed in writing to course websites." (p. 12). The enduring nature of online written communication can here be contrasted with the assumed transience of the spoken word in the synchronous seminars afforded by contemporary Net-based technology.

Joinson (2003, pp. 182-183) comments that increased ease of self-disclosure may be associated with perceived anonymity and an associated reduced accountability but suggests that the introspection involved in writing might increase self-awareness, leading to changes in how the individual sees himself or herself. Joinson (2001) experimented with the effect of adding a video channel to a text chat and found that visually anonymous participants disclosed significantly more information about themselves than non-visually anonymous participants and also that higher levels of private self-awareness (seeing oneself in a mirror) in combination with high public self-awareness (i.e., a lack of anonymity including a video link to the interlocutor) decreased participants' willingness to self-disclose. Shepherd and Edelmann (2005) found a correlation between social phobia and social anxiety and a preference for Net-based communication for social purposes, while Rice and Markey (2009) discovered in an experiment that a group of introverted women found text-based, anonymous, Net-based communication less stressful than face-to face communication. It is not clear how far the "reduced media richness" (Hudson \& Bruckman, 2002) of the online environment, together with the possibility of further limiting the modes used (by non-use of a webcam), will be enough to trigger a disinhibitory effect.

In face-to-face EFL teaching, relatively few students dare to spontaneously express their thoughts in front of the class, at least partly due to their reluctance to speak English in front of their teacher and peers. In Net-based seminars, there is, as Conrad (2002a) put it, "no distance: you cannot run and you cannot hide" (p. 11). It is very clear if a student remains silent throughout an online seminar as the nature of the technology leads to teachers regularly asking all students for input of some kind.

\section{Language Learning}

Current thinking about how languages are learned includes both Krashen's (1985) input hypothesis, which posits that learners need input that is just a little more complex than they understand but from which meaning can be inferred, and Swain's (1985) work on the role of interaction, which suggests that learners need the opportunity to produce comprehensible output. Sociocultural factors and the social perspective of learners are widely believed to be an integral part of second-language acquisition (Swain \& Deters, 2007). It is well known that affective factors such as inhibition are a disadvantage to the language learner. Early studies replicating the informal experiments of generations of language students found that inhibition-lowering drugs such as alcohol (Guiora, Beit-Hallahmi, Brannon, Dull, \& Scovel, 1972) and Valium (Guiora, Acton, Erard, \& Strickland, 1980) improved oral production skills in a foreign language. Naiman et al. (1995) found that "an indication by the student of his general classroom personality, including fear of being laughed at, or being embarrassed when speaking, or not putting up his hand until he was certain he knew the response, etc." (p. 148) was a good predictor of language learning success. Individual factors that charac- 
terize good language learners include being willing to take risks. Rubin (1975) includes the following in his list of strategies for aspiring "good language learners": "The good language learner is often not inhibited. He is willing to appear foolish if reasonable communication results. He is willing to make mistakes in order to learn and to communicate.” (p. 47).

Hudson and Bruckman (2002) relate Guiora's claim from 1972 that giving up control is necessary to learning a new language to the virtual environment and to disinhibition research in Net-based environments, such as Joinson's work $(1998,2003)$. They found that students who were reluctant to speak the foreign language in classroom situations were active in real-time text chats with their classmates in the foreign language. Hudson and Bruckman account for this as a reflection of the reduced media richness of the text-based environment and the fact that there is a difference in immediacy caused by the delay between message composition and message receipt. They have looked at several online language-learning studies that point to benefits (e.g., Beauvois, 1997; Beauvois \& Flege, 1996). They warn that all of these have been set in text-based environments, and they fear that the introduction of richer online environments might impede the disinhibition advantages associated with the text-based situation.

\section{Social Presence}

The experience of liminality in the online seminar will be proportional to the perceived reality of the seminar experience, which in turn will be associated with the degree of perceived presence in the seminar. Lombard and Ditton (1997) discuss both the use of a medium to transport the user to a place and the physical or psychological immersion of the user in the space represented through the medium. In the Adobe Connect seminar room, there is a room metaphor in operation, which is designed to set students into an appropriate mode on entering the seminar space. Although there is no graphic support for this, students are encouraged to view the Connect portal page as a corridor with doors to classrooms, such that they are only allowed to open the door of their own seminar at the appropriate time to avoid disturbing other classes. Presence in this context is defined as the subjective experience of being in one place or environment, even when one is physically situated in another (Witmer \& Singer, 1998). Zhao (2003) defines one kind of co-presence as being together with another person in a technology-mediated environment, along with the sense of togetherness perceived in that context, and claims that the simultaneous presence of the participants in the seminar is crucial for the sociocommunicative learning that is expected to take place. The communitas of all being in the same boat (although actually in wildly different times and places) is an integral part of the synchronous seminar experience.

While Hudson and Bruckman (2002) warn online educators not to attempt to recreate the classroom experience, maybe this is just what they need to do to enhance the positive effects of liminality. Taking this position to its extreme, educators operating within an enriched virtual environment, such as Second Life, report that their students are immersed and interactive, but these virtual worlds have proved to be a disappointment to many early adopters (Stieglitz, Lattemann, \& Fohr, 2010) and the potential for exciting learning environments has not been realized. The virtual learning environment offered by desktop 
video-conferencing systems such as Adobe Connect is in one sense not as realistic as a virtual world, but it does have the advantage of focussing the attention of the participants on what they are doing, rather than on the transportation of their avatars. The use of a headset reduces the audio input from the real world surrounding the student and makes the sounds that surround the other participants who have active microphones at least as salient as the real-world sounds in the student's own physical environment. As well as listening carefully to the audio channel, attention must be paid to other modes, such as the video images of the other participants, the whiteboard, and the text chat, in order to cope with and compensate for the sometimes distorted signal and the unfamiliar accents of the other participants (Cunningham et al., 2010). The online seminar experience in this kind of setting is demanding for teacher and students alike.

Most of the existing research dealing with social presence in online learning (e.g., Garrison, Anderson, \& Archer, 2001; Swan \& Shih, 2005; Shea, Li, \& Pickett, 2006) is old already and based in asynchronous, text-based learning contexts. The kind of social presence available to students in these settings is different from that in contemporary synchronous multimodal seminar environments. The latter simulate face-to-face teaching much more closely, but I argue that the differences that do exist are such that the students' perception of selfdisclosure is less than in the face-to-face environment.

Mennecke, Triplett, Hassall, and Conde (2010) discuss embodied social presence and claim that the use of an avatar is important in the suspension of disbelief needed for the creation of the feeling of presence in computer-mediated environments. On the same note, Senem (2009) discovered that students found it difficult to see their classmates as real at the beginning of the course and that they actively looked for pictures of their classmates to have an idea of what they looked like. Both these findings suggest that visual information about fellow students and teachers may be important for constructing a perception of social presence. In the setting described here, the students can see each other and the teacher if they have activated their webcams.

\section{Quantum Education?}

Hudson and Bruckman (2002) expressed a fear that a richer multimodal environment might not produce the disinhibitory effects seen in text-based interaction, yet it may well be that the liminality of the online seminar room can generate the same kind of effects. The disinhibition associated with liminality could be a very positive effect if it were to be applied to language learning. Of course, in the case of the octagonal room presented at the beginning of this paper, the participants are not only "betwixt and between, neither here nor there" as Turner put it, but rather both here and there. They are in their physical environment, feeling the heat or cold and humidity or dry air, hearing the sounds around them, and they are also, simultaneously, in the virtual environment, hearing and seeing their classmates and teacher, and even hearing the sounds in each participant's physical environment. In the manner of the entangled twins of quantum mechanics, where an action performed on a particle in one place will affect its twin at a remote location, the thoughts, words, and actions of each participant will affect the thoughts, words, and actions of those 
thousands of kilometres away yet connected to them by the co-presence of the synchronous online seminar room.

So for our students in the virtual octagonal room, there is not a true removal from the everyday environment; it still surrounds them and clamours for their attention. The temporary suspension of disbelief that allows them to take part in this meeting of the minds, like the "higher-level beings of pure energy" of some 1960s space opera, is but an illusion. As they are not really removed from their everyday surroundings, they are not really freed from the norms and expectations to which they are generally subject. At the same time, they have the security of being in familiar surroundings and can maintain a measure of protection from the total self-revelation required by physical presence, especially if they restrict the modes of their participation to exclude video. Unlike campus students who have made a physical transition to the learning environment, they may well be still surrounded by people associated with their roles in their physical environment. These friends, colleagues, or family members, whose ability to overhear them and to peer over their shoulder to see what is going on in the virtual environment, may severely hamper the students' freedom to immerse themselves in the virtual learning environment and to abandon themselves to its intellectual delights. The participants in the virtual learning environment may well experience a meeting of minds, but, at the same time, they are always tethered to their physical reality. 


\section{References}

Angeli, A. D., \& Brahnam, S. (2008). I hate you! Disinhibition with virtual partners. Interacting with Computers, 2O(3), 302-310.

Apostolopoulos, Y., Sonmez, S., \& Yu, C. H. (2002). HIV-risk behaviours of American spring break vacationers: A case of situational disinhibition? International Journal of STD \& AIDS, 13(11), 733-743.

Beauvois, M. H. (1997). Computer-mediated communication (CMC): Technology for improving speaking and writing. In M. D. Bush \& R. M. Terry (Eds.), Technologyenhanced language learning (pp. 165-184). Lincolnwood, IL: National Textbook Company.

Beauvois, M. H., \& Fledge, J. (1996). Personality types and megabytes: Student attitudes toward computer-mediated communication (CMC) in the language classroom. CALICO Journal, 13(2/3), 27-45.

Conrad, D. (2002a). Deep in the hearts of learners: Insights into the nature of online community. Journal of Distance Education, 17(1), 1-19.

Conrad, D. (2002b). Engagement, excitement, anxiety, and fear: Learners' experiences of starting an online course. American Journal of Distance Education, 16(4), 205226.

Cunningham, U., Beers Fägersten, K., \& Holmsten, E. (2010). “Can you hear me, Hanoi?” Compensatory mechanisms employed in synchronous Net-based English language learning. The International Review of Research in Open and Distance Learning, 11(1), 161-177.

Dyer, R., Green, R., Pitts, M., \& Milward, G. (1995). What's the flaming problem? or Computer-mediated communication: Deindividuating or disinhibiting? In M. A. R. Kirby, A. J. Dix, \& J. E. Finlay (Eds.), Proceedings of the HCI'95 Conference on People and Computers $X$ (pp. 289-302), Huddersfield, UK: Cambridge University Press.

Eiser, J., \& Ford, N. (1995). Sexual relationships on holiday: A case of situational disinhibition? Journal of Social and Personal Relationships, 12(3), 323-339.

Ford, N., \& Eiser, J. R. (1996). Risk and liminality: The HIV-related socio-sexual interaction of young tourists. In S. Clift \& S. J. Page (Eds.), Health and the international tourist. New York, NY: Routledge.

Garrison, D. R., Anderson, T., \& Archer, W. (2001). Critical thinking, cognitive presence, 
and computer conferencing in distance education. American Journal of Distance Education, 15(1), 7-23.

Gennep, A. van (1960). The rites of passage (M. Vizedom \& G. Caffee, Trans.). London, UK: Routledge and Kegan Paul.

Guiora, A. Z. (1972). Construct validity and transpositional research: Toward an empirical study of psychoanalytic concepts. Comprehensive Psychiatry, 13(2), 139-150.

Guiora, A.Z., Acton, W. R., Erard, R., \& Strickland, F.W.(1980). The effects of benzodiazepine (Valium) on permeability of language ego boundaries. Language Learning, 3o(2), $351-363$.

Guiora, A. Z., Beit-Hallahmi, B., Brannon, R. C. L., Dull, C. Y., \& Scovel, T. (1972). The effects of experimentally induced changes in ego states on pronunciation ability in a second language: An exploratory study. Comprehensive Psychiatry, 13(5), $421-428$.

High, A. C., \& Caplan, S. E. (2009). Social anxiety and computer-mediated communication during initial interactions: Implications for the hyperpersonal perspective. Computers in Human Behavior, 25(2), 475-482.

Hudson, J. M., \& Bruckman, A. (2002). Disinhibition in a CSCL environment. In G. Stahl (Ed.), Proceedings of Computer Support for Collaborative Learning (CSCL) 2002 (pp. 629-630). Boulder, CO: Routledge.

Joinson, A. N. (1998). Causes and implications of disinhibited behaviour on the Net. In J. Gackenbach (Ed.), Psychology and the internet: Intrapersonal, interpersonal, and transpersonal implications (pp. 43-6o). San Diego, CA: Academic Press.

Joinson, A. N. (2001). Self-disclosure in computer-mediated communication: The role of self-awareness and visual anonymity. European Journal of Social Psychology, 31(2), 177-192.

Joinson, A. N. (2003). Understanding the psychology of internet behaviour. Basingstoke, UK: Palgrave Macmillan.

Kiesler, S., \& Sproull, L. (1992). Group decision-making and communication technology. Organization Behavior and Human Decision Processes, 52, 96-123.

Krashen, S. (1985). The input hypothesis: Issues and implications. London, UK: Longman.

Lippman, S. A., Pulerwitz, J., Chinaglia, M., Hubbard, A., Reingold, A., \& Diaz, J. (2007). Mobility and its liminal context: Exploring sexual partnering among truck drivers 
crossing the southern Brazilian border. Social Science \& Medicine, 65(12), 24642473 .

Lombard, M., \& Ditton, T. (1997). At the heart of it all: The concept of presence. Journal of Computer-Mediated Communication, 3(2).

Mennecke, B. E., Triplett, J. L., Hassall, L. M., \& Conde, Z. J. (2010). Embodied social presence theory. Proceedings of the 43rd Hawaii International Conference on System Sciences (pp. 1-10). Koloa, Kauai, HI: IEEE Computer Society.

Naiman, N., Fröhlich, M., Stern, H. H., \& Todesco, A. (1995). The good language learner. Clevedon, UK: Multilingual Matters.

Rice, L., \& Markey, P. M. (2009). The role of extraversion and neuroticism in influencing anxiety following computer-mediated interactions. Personality and Individual Differences, 46(1), 35-39.

Roberts, L. D., Smith, L. M., \& Pollock, C. M. (2000). 'u r a lot bolder on the net': Shyness and Internet use. In W. R. Crozier (Ed.), Shyness: Development, consolidation \& change (pp. 121-138). Series: Routledge Progress in Psychology. London: Routledge.

Rubin, J. (1975). What the "good language learner" can teach us. TESOL Quarterly, 9, 4151.

Senem, Y. (2009). Social presence in the web-based classroom: Implications for intercultural communication. Journal of Studies in International Education, 13(1), 46-66.

Shea, P., Li, C. S., \& Pickett, A. (2006). A study of teaching presence and student sense of learning community in fully online and web-enhanced college courses. The Internet and Higher Education, 9(3), 175-190.

Shepherd, R.-M., \& Edelmann, R. J. (2005). Reasons for Internet use and social anxiety. Personality and Individual Differences, 39(5), 949-958.

Sproull, L., \& Kiesler, S. (1986). Reducing social context cues: Electronic mail in organization communication. Management Science, 32, 1492-1512.

Stieglitz, S., Lattemann, C., \& Fohr, G. (2010). Learning arrangements in virtual worlds. Proceedings of the 43rd Hawaii International Conference on System Sciences (pp. 1-7). Koloa, Kauai, HI: IEEE Computer Society.

Suler, J. (2004). The online disinhibition effect. Cyberpsychology and Behavior, $7(3)$, $321-326$. 
Swan, K., \& Shih, L. F. (2005). On the nature and development of social presence in online course discussions. Journal of Asynchronous Learning Networks, 9(3), 115-136.

Swain, M. (1985). Communicative competence: Some roles of comprehensible input and comprehensible output in its development. In S. Gass \& C. Madden (Eds.), Input in second language acquisition (pp. 235-253). Rowley, MA: Newbury House.

Swain, M., \& Deters, P. (2007). "New" mainstream SLA theory: Expanded and enriched. Modern Language Journal, 91(5), 820-836.

Thurlow, C., Lengel, L., \& Tomic, A. (2004). Computer-mediated communication. London, UK: Sage Publications.

Turner, V. (1967). The forest of symbols: Aspects of Ndembu ritual. Ithaca, NY: Cornell University Press.

Turner, Victor Witter (1969). The ritual process: Structure and anti-structure. London, UK: Routledge \& Kegan Paul.

Wingate-Lewinson, T., Hopps, J., \& Reeves, P. (2010). Liminal living at an extended-stay hotel: Feeling "stuck" in a housing solution. Journal of Sociology \& Social Welfare, $37(2), 9-35$.

Witmer, B. G., \& Singer, M. J. (1998). Measuring presence in virtual environments: A presence questionnaire. Presence, $7(3), 225-240$.

Zhao, S. (2003). Toward a taxonomy of copresence. Presence: Teleoperators and Virtual Environments, 12(5), 445-455.

\section{Athabasca University $\mathbf{1}$}

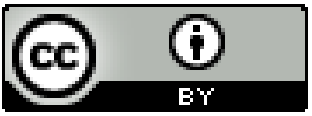

